\begin{tabular}{lllll}
\hline Motrivivência & Ano XX, & No 31, P. & 301-318 & Dez./2008 \\
\hline
\end{tabular}

\title{
Conteúdos da Educação Física no Período Pré-Olimpíada de 2016: avanço?
}

\author{
Rafael da Silva Mattos \\ Licenciado em Educação Física pela Universidade \\ do Estado do Rio de Janeiro (UERJ), Licenciando em \\ Filosofia pela UERJ, Doutorando em Saúde Coletiva (Ciências \\ Humanas e Saúde) pela UERJ e bolsista do CNPq.Instituto de \\ Medicina Social da Universidade do Estado do Rio de Janeiro \\ (UERJ) e Instituto de Educação Física e Desportos da UERJ \\ profmattos2010@gmail.com
}

\section{Resumo Abstract}

O objetivo deste artigo é discutir o discurso hegemônico das práticas

esportivas como conteúdos da educação física escolar. Diante de toda euforia pela direito de sediar

os jogos olímpicos em 2016, a educação física recebe a missão de preparar os novos atletas e futuros campeões. Mas seria isso um avanço na concepção de educação física? Que conteúdos são subestimados em prol dos esportes?

Palavras-chave: Esporte; Olimpíadas; The aim of this paper is to discuss the hegemonic discourse of sports content such as physical educacion. Before all the excitement right to host the Olympic Games in 2016, physical education received a mission to prepare young athletes and future champions. But is this a advance in the physical education? Which contents are underestimated in favor of sports?

Keywords: Sport, Olympic, Phisical Education

Educação Física. 


\section{Introdução}

Que cultura corporal se propõe na educação física escolar? Como se incorporam os usos do corpo, das técnicas, mas também outros elementos mais informais, lúdicos, estéticos, simbólicos, pulsionais nas aulas de educação física? As práticas esportivas devem ser o suporte hegemônico da educação física escolar? Em outros termos, como desenvolver todas as dimensões da corporeidade? Tomarei como base o texto de Lefèvre (2000) para pensar os conteúdos da educação física escolar num período de grande euforia brasileira, em especial da classe política, pela conquista brasileira de sediar a Olimpíada de 2016. A supervalorização do esporte como prática e discurso capaz de trazer redenção para o Rio de Janeiro traz que fardo para a educação física escolar? A redução da educação física ao esporte para fabricar atletas é apagar a corporeidade da vivência cotidiana. É negar a própria educação física enquanto cultura do movimento corporal.

Ao abrir a revista VEJA (2009) e a revista VEJA RIO (2009) me deparei com extensas reportagens sobre o fato do Rio de Janeiro ter conquistado o direito de sediar os Jogos Olímpicos de 2016. Sem dúvida, conquista inédita para nosso país e oportunidade de de- senvolvimento da cidade do Rio de Janeiro (novos investimentos e melhorias na urbanização) e do esporte no Brasil.

VEJA (2009) afirma que o Rio de Janeiro irá investir 23,2 bilhões de reais somando Copa do Mundo de 2014 e Olimpíadas de 2016. VEJA RIO (2009) divulga o orçamento da cidade do Rio de Janeiro para as Olimpíadas de 14,43 bilhões de reais, enquanto Tóquio pretendia investir 6,42 bilhões de reais, Madri 6,13 bilhões de reais e Chicago 4,82 bilhões de reais. Serão cerca de 5,5 bilhões para a área de transportes, 2,6 bilhões para infra-estrutura esportiva, 1,3 bilhões para energia elétrica e telecomunicações, 1,3 bilhões para segurança pública e 1,3 bilhões para meio ambiente. Educação? Saúde? Não sabemos o que acontecerá.

Abrahão (2005) ao analisar os investimentos públicos na área de educação no Brasil, observa que se situam em torno de $4 \%$ do Produto Interno Bruto (PIB). Nos países da Organização de Cooperação para o Desenvolvimento Econômico (OCDE) a média é de 5,3\% do PIB. Os gastos brasileiros em educação não são inferiores apenas aos países desenvolvidos (Dinamarca $-8,5 \%$ do PIB; Suécia - 7,3\% do PIB), mas também a outros países da América Latina (Argentina $-4,8 \%$ do PIB; Paraguai $-4,5 \%$ do PIB). 
Os investimentos préOlimpíada estão voltados para expansão do metrô, construção de linhas BRT (Bus Rapid Transit), reforma do Aeroporto Internacional Tom Jobim (Galeão), reforma do Aeroporto Santos Dumont, construção do Arco Metropolitano para desafogar o trânsito, revitalização da zona portuária, despoluição da Lagoa Rodrigo de Freitas, Baía de Guanabara e lagoas de Jacarepaguá, construção de um Estádio Aquático Olímpico na Barra da Tijuca, reforma e ampliação do Sambódromo, reforma do estádio de futebol Mário Filho e do estádio de futebol João Havelange. É claro que essa é uma grande conquista não apenas para o Rio de Janeiro, mas para o Brasil.

$\mathrm{O}$ que se torna interessante, quando não assustador, é o descaso e o abandono com alguns setores públicos como educação e saúde. Não seria esse o momento para pensar em reformas estruturais na educação? Não seria esse o momento para tematizar os conteúdos e objetivos da educação física? Haverá investimento em infraestrutura esportiva adequada para que profissionais de educação física possam desenvolver um trabalho de qualidade ou a responsabilização será cada vez maior dos alunos e profissionais?

Para termos dimensão do descaso, o número de escolas com quadras de esportes não chega nem a $50 \%$ na região sudeste, alcançando índices ínfimos de 8\% no Nordeste e $9 \%$ no Norte. Isso sem contarmos a escassez de laboratórios de ciências, que não ultrapassam $1 \%$ das escolas públicas da região norte e nordeste, e $12 \%$ no sudeste. Até mesmo no quesito biblioteca, a educação brasileira vai mal. Só $10 \%$ das escolas públicas do Norte e Nordeste possuem bibliotecas, enquanto $27 \%$ no Sudeste. Como um país com essa realidade pode-se tornar potência olímpica ou potência econômica no cenário internacional? (PINTO, 2007).

Os Congressos Nacionais de Educação e o Fórum Nacional em Defesa da Escola Pública sempre lutaram pela redefinição das políticas de educação pública que hoje são políticas estritamente econômicas, pela ampliação do \% do PIB destinado a educação de $4 \%$ para $7 \%$, conforme previsto no Plano Nacional de Educação, pela necessidade de garantir um piso salarial nacional e por um plano nacional de carreira para os profissionais da educação (LEHER, 2005).

Sampaio e Marin (2004) ressaltam que o cálculo bruto da média salarial de docentes da educação básica brasileira (incluindo o professor de Educação Física, é claro) é de $R \$ 529,92$, numa escala que varia de $R \$ 221,22$ (Paraíba) 
a $R \$ 1364,30$ (Distrito Federal). Enquanto todos comemoram nossa futura Olimpíada, a precarização do trabalho docente aumenta implicando em pauperização da vida pessoal do professores. Outro exemplo de descaso é o tamanho das turmas. $\mathrm{O}$ número médio de alunos por turma chega a 28,6 , numa escala que varia de 22,2 (Roraima) a 43,0 (Sergipe) no ensino fundamental. Esses números estão bem acima da média obtida pelos países desenvolvidos, 14 a 15 alunos por turma.

$\mathrm{Na}$ educação superior os problemas também são grandes. Leher e Lucas (2001) afirmam que a remuneração docente está cada vez mais precária, na qual os vencimentos básicos variam, em média, entre 20 e $28 \%$ do total recebido. Enquanto alguns países estimulam que os atletas sejam universitários, oferecendo bolsas de estudos, no Brasil, nossos atletas abandonam os estudos em virtude dos horários e exigências de treinamento.

Podemos perceber que há vários problemas estruturais na educação brasileira que não serão resolvidos de imediato, nem serão discutidos nesse artigo. Mas não seria exatamente esse o momento para colocarmos em pauta essas questões de cunho político? Gostaria, no entanto, de chamar atenção não apenas para o descaso com a educação física, mas em especial para o discurso da educação física escolar como produtora de novos atletas para as Olimpíadas. Como afirma Bordeleau (1985), de todos os lugares de expressão da corporeidade, o esporte se tornou o mais nítido. O sistema esportivo faz do corpo um novo modelo de identidade. No entanto, precisamos ter um olhar crítico esse modelo esportivo tentando compreender os avanços e retrocessos que se estabelecem.

\section{O corpo e a cultura}

Pensar o corpo como um objeto cultural é de um lado, deslocar as representações comuns que se ligam ao corpo e, por outro lado, tentar aprender um sistema complexo de rituais, de trocas, de valores, de símbolos, ou seja, tentar compreender esse substrato no qual a cultura se incorpora. A relação com o corpo deve ser lida igualmente sob os sinais de poderes, desejos e pulsões. Essa fascinação-repulsão pelo corpo parece justificar em cada o projeto das instituições que se empenham em purificá-lo, domesticá-lo, assujeitálo para produzir, fragmentá-lo para racionalizá-lo em objeto científico (LEFÈVRE, 2000).

Foi necessário esperar que Marcel Mauss, sobrinho do pai da sociologia Émile Durkheim, desse o primeiro passa na construção de 
uma antropologia do corpo para que pudéssemos compreender a influência definitiva da cultura no somático. O corpo é antes de tudo o substrato social do ser humano, ele forma a primeira matéria das expressões humanas, como as mímicas, as posturas, os gestos e os movimentos. O corpo é a linguagem anterior a fala. Não é sem razão que Piaget $(1963,1990,2000)$ chama o primeiro período de desenvolvimento do ser humano de "sensório-motor". O conhecimento é construído através de impressões que chegam ao organismo por meio de órgãos dos sentidos e do aparelho motor. A criança age sobre aquilo que vê, ouve, toca e que chega à sua boca. Do reflexo de preensão forma-se um esquema de agarrar, do reflexo de sucção forma-se um esquema de sugar, morder. À medida que a criança vai utilizando seu corpo, o real vai se construindo.

Mauss (1974) criou o conceito de "Técnicas Corporais" e o utilizou pela primeira vez em uma palestra em 1930 que só foi publicada em 1950 na França e em 1974 no Brasil. Técnicas Corporais são as maneiras pelas quais os seres humanos culturalmente utilizam seus corpos. Todos os gestos corporais são técnicas. Antes do homem produzir qualquer técnica para intervir na natureza, ele utilizou o seu corpo como instrumentos cultural. Nesse sentido, corpo é um produto das técnicas corporais culturalmente aprendidas.

Elias $(1993,1994)$ também colocou em evidência os usos diferenciais do corpo entre os diversos grupos sociais. Ele ressalta o caráter social e cultural de vários comportamentos desde os mais simples até os mais públicos e refinados. $\mathrm{Na}$ sociedade de corte européia se difundiram as regras de civilidade que adotamos em matéria de estilo, de educação dos sentimentos, de uso e postura do corpo, de linguagem. Para Elias $(1993,1994)$ a conduta e o comportamento civilizado aparece a partir de uma economia psíquica que interioriza o autocontrole. A civilização dos costumes passa a regular os movimentos da corporeidade (as maneiras à mesa, a satisfação das necessidades naturais, a flatulência, o escarro, as relações sexuais, o pudor, as manifestações de violência). As sensibilidades modificam-se. Quando o corpo se modifica, o homem se modifica. $\mathrm{O}$ processo de civilização está, portanto, diretamente relacionado com a capacidade psíquica do homem de dominar e controlar suas pulsões e desejos predominantemente corporais nas suas experiências sociais.

Já Boltanski (1971, 2004) coloca em evidência a culturas somáticas segundo as classes sociais que pertencemos, que engendram 
percepções muito diferentes do corpo. Existe um código inconsciente de boas maneiras de cuidar do corpo, profundamente interiorizado, e comum a todos os membros de um grupo social determinado. Isso contraria qualquer idéia de que a prática corporal, como a esportiva, possa ser universal. Nas classes populares, o esporte é essencialmente uma distração praticada em grupo (esportes de equipes) para os adolescentes do sexo masculino, enquanto nas classes superiores, privilegia-se os esportes individuais, as mulheres e as pessoas de mais idades. $\mathrm{O}$ esporte tem uma função de manter o indivíduo "em forma", ou seja, adquirir ou conservar um corpo conforme os cânones de beleza em vigor das classes superiores.

Duret e Roussel (2003) ainda acrescentam que quando faltam trunfos econômicos e culturais nas classes populares, o corpo pode se tornar um vetor privilegiado de identidade. Contra a vergonha e a humilhação escolar, a força física, e até o sucesso nos esportes, restaura a estima do indivíduo e lhe dá a chance de ser "alguém", embora ainda seja considerado um "bronco", "bruto".

Wacquant (2002) chega a afirmar que não devemos apenas fazer Sociologia do Corpo, mas Sociologia a partir do corpo, considerando-o como organismo so- cializado e sensório de construção social que põe em primeiro plano a primazia cinética do mundo que nos faz membros reconhecidos de um dado universo.

O corpo não é somente um conjunto de músculos e ossos que podemos treinar. O corpo é também o self. A identidade do corpo e do self é talvez mais claramente ilustrada pelas mudanças corporais. Os conceitos de self mudam na puberdade, na gravidez e na menopausa. As mudanças corporais mudam o self. No corpo carregamos nossa identidade pessoal e social (SYNNOT, 1993.)

\section{O corpo na educação física escolar}

Como se faz a educação do corpo na escola? Qual cultura do corpo a educação física propõe? Como levar em conta as mudanças culturais? Quais usos a instituição escolar faz dessas mudanças históricas para alargar a tessitura de nossa corporeidade? Se o corpo é um traço de nossa cultura, uma cultura que muda, se diversifica e da qual as transformações afetam os modelos de referencia a partir dos quais se constroem as relações com o corpo, como a educação física se posiciona perante isso? (LEFÈVRE, 2000).

O corpo é um objeto tão familiar, tão presente que é difícil 
distanciá-lo como objeto epistemológico. Diante disso, como interrogar esse objeto, essa matriz da nossa relação com o mundo, de outra maneira a não ser através de uma abordagem sócio-antropológica. Produtor de sentidos, o corpo tece a ligação social, ele revela nossas culturas através da corporeidade humana.

Para Le Breton (2006), as lógicas sociais e culturais se propagam no corpo. Por isso, podemos produzir uma sociologia do corpo. O homem constrói socialmente o seu corpo na interação com os outros, o que nos evidencia que a corporeidade é produto da cultura. Como fenômeno social e cultural, essa corporeidade deve ser estudada em todas as suas dimensões da vida cotidiana, não se limitando a produção de um corpo maquínico ou esportista.

Brugnerott e Simões (2009) corroboram com nossa discussão ao afirmarem que a formação profissional em Educação Física deveria ultrapassar o foco de intervenção apenas por práticas corporais que envolvem o esporte, e ampliar suas possibilidades para, além disso, discutir o que representa cada manifestação corporal na construção do ser humano. Em seu estudo sobre currículos de formação do profissional de Educação Física, os autores percebem que as alterações ideoló- gicas mais recentes que formataram os projetos político-pedagógicos, embora estejam de acordo com o movimento de promoção da saúde e qualidade de vida, ainda valorizam em demasia a idéia de que compete ao profissional de Educação Física dar ênfase, em sua prática, à prescrição, ao monitoramento e à avaliação de exercícios físicos através das bases fisiológicas do ser humano.

Colocando o corpo no centro de nossas preocupações, o caminho adotado se emprega a retomar qual tipo de corporeidade propõe um curso de educação física. Que abertura cultural precisamos para construir uma educação corporal diversificada e para encarar todas as possibilidades do corpo? Ensinase na educação física, o corpo fora do lugar, fora da norma? Ensina-se a diferença, a multiplicidade, o devir? Ensina-se o lúdico, o prazer?

O discurso hegemônico na educação física coloca o prazer numa posição paradoxal: é ao mesmo tempo marginal e, no entanto, central para as concepções de educação física. Pensar a lógica educacional sem o prazer do processo de ensino-aprendizagem é pensar a própria vida sem o prazer. Dos utilitaristas ingleses (BENTHAM, 1988; MILL, 2005) à psicanálise (FREUD, 1962, 1968, 1981), não há como excluir o prazer da vida humana. 
Liotard (1997) afirma que o prazer tem sido dispensado na escola ou é teorizado na perspectiva de aplicação muito ampla, de tal forma que a busca do prazer é rejeitada pelos métodos de ensino. Como regatar o prazer no imaginário escolar? Essa á uma questão que precisamos recolocar no debate, segundo Marie (1997). O prazer pode ser o efeito de uma atividade escolar obrigatória, mas isso se ele estiver em convergência com um modelo de corpo mais livre.

Os modelos do corpo na escola estão calcados sobre uma referência cultural dominante, aquela da lógica de ordem própria do Ocidente. Toda nossa educação é em certa medida, o estabelecimento da forma de nosso corpo segundo as exigências da sociedade, o que implica ao mesmo tempo uma modelagem social do corpo, mas também por um efeito recursivo, uma construção do social pelas diferentes questões corporais.

Segundo Le Breton (2002), na civilização antiga e medieval predominava a representação social e coletiva do homem como um ser que não se distinguia da comunidade e do cosmos em que estava inserido. Ele estava amalgamado com a multidão de seus semelhantes sem que sua singularidade o convertesse em um "indivíduo" no sentido moderno do termo. O homem, inseparável de seu corpo físico, era percebido como incluso dentro das forças que regem o mundo. Para que a individuação, através do corpo, pudesse ocorrer seria preciso esperar o desenvolvimento do individualismo moderno. Somente, então, o corpo apareceria separado do homem. O renascimento, as revoluções burguesas, a reforma protestante e o iluminismo foram os propagadores mais fervorosos da nascente visão de mundo que coloca o indivíduo no centro. Nascia, gradativamente, o sujeito moderno liberal, livre, autônomo.

A individuação do homem se produz paralelamente a dessacralização da natureza. O corpo se converte na fronteira entre um homem e outro. Ao perder sua raiz na comunidade, ao separar-se do cosmos, o homem do Renascimento descobre que carrega um corpo. O corpo não é mais símbolo da presença humana inseparável do homem e do cosmos, mas é um instrumento, um acessório do homem. A definição moderna do corpo implica que o homem se separa desse cosmos, dos outros e de si mesmo. Mais do que isso, o corpo precisava ser trabalhado, moldado, adestrado, domesticado. O conceito de "individualidade" nascente através de um conjunto de relações de poder e saber converte-se no conceito de "subjetividade". O EU interior e o 
EU exterior se tornam entidades distintas, cabendo à sociedade treinar e civilizar esse EU exterior. Os desejos, pulsões, instintos, impulsos devem ser controlados para o que o EU interior sempre prevaleça. $\mathrm{O}$ famoso texto de Kant (2004) sobre a educação física ressalta a necessidade de eliminar a animalidade dentro do sujeito e torná-lo humano. Caberia à educação conter a animalidade humana, de modo que o homem deixasse de ser um selvagem.

Foucault (1976, 1989, 1993) irá tratar dos mecanismos e tecnologias de poder-saber que produziram esse sujeito moderno e, por conseguinte, seu corpo dócil. Ao escrever Vigiar e Punir, publicado em 1975, ele faz uma genealogia do indivíduo moderno a partir de uma história biopolítica dos corpos. São as relações de poder-saber que constroem a individualidade e a identidade do corpo, impondo-lhe uma verdade ontológica que devemos reconhecer. É uma forma de poder que faz dos indivíduos sujeitos com sua própria identidade.

Fournier (2005) ressalta que em Paris, no século XVIII, milhares de pessoas se reuniam para assistir os condenados, ligados uns aos outros por suas algemas de ferro. Os expectadores observavam os suplícios públicos com muita atenção. A partir de 1837, os detentos foram transportados por viaturas e retira- dos do olhar da multidão. Os rituais públicos dos suplícios desapareciam aos poucos, enquanto surgiam as detenções penais. Estávamos passando de uma arte de punir para outra arte de punir. Em Vigiar e Punir, Foucault (1993) explica porque a burocracia jurídico-penal foi progressivamente substituindo a punição-espetáculo do Antigo Regime. A forca, os instrumentos de esquartejamento, a guilhotina e a roda desapareciam para dar lugar a outras atividades punitivas: prisão, reclusão, trabalhos forçados, deportação.

Tratava-se de uma crise na economia das punições. Os reformadores do sistema penal queriam não apenas punir, mas punir melhor. O essencial era dissuadir todos aqueles que pensassem se voltar para o crime. A pena ideal deveria ser mínima para aquele que a sofre, e máxima para aquilo que ela representa. Essas regras deslocavam a aplicação do poder: não mais o corpo supliciado, mas o corpo produtivo através do qual se visa o controle social.

A punição corporal foi progressivamente substituída pelo cárcere. Trata-se menos de supliciar do que de corrigir, graças a um sistema de ortopedia social. Entretanto, essa humanização não foi produto de uma benevolência dos governantes, mas uma reação diante da incapacidade do Antigo 
Regime de enfrentar as profundas modificações que ocorriam na sociedade. Percebia-se que era mais eficaz vigiar do que punir. Abriase assim a era da normalização: instituindo-se normas, produzindo a figura do delinqüente e justificando um tipo de controle fechado. $\mathrm{O}$ século XVIII-XIX inicia uma forma inédita de disciplina social (LE FRANC, 2005).

Explosão demográfica, revolução industrial, urbanização, ascensão do capitalismo. Era preciso uma forma de poder-saber mais eficaz para controlar as populações cada vez mais numerosas e lidar com o aparecimento e desenvolvimento dos aparelhos de produção. A resposta a esse problema toma a forma de uma microfísica do poder, caracterizada pelas novidades dessa sociedade disciplinar. O crescimento da economia capitalista fez nascer um novo poder-saber.

Qual é o tipo de investimento do corpo que é necessário e suficiente ao funcionamento de uma sociedade capitalista?, pergunta Foucault (1993). O poder penetrou no corpo, materializandose. Trata-se de uma eficácia dos movimentos. Podemos chamar de "disciplinas" esses métodos, essas técnicas que autorizam o controle minucioso das operações do corpo. Foucault tratou das "disciplinas" no curso de 1972-1973 (A Sociedade
Punitiva), no curso de 1973-1974 (O poder psiquiátrico), no curso de 1974-1975 (Os Anormais) e no livro Vigiar e Punir de 1975.

O poder se materializa no corpo dos indivíduos através de técnicas disciplinares. O corpo é disciplinado e docilizado através do olhar hierárquico, exame, seriação do espaço, esquadrinha mento do tempo, sanções normalizadoras e vigilância permanente. As disciplinas se tornam, no século XVIII, as formas gerais de dominação nos quartéis, hospitais, escolas, usinas e prisões. O primeiro imperativo é o de repartir os indivíduos em um espaço segundo um princípio de fechamento: é o momento do grande aprisionamento. É preciso concentrar as massas (quer sejam elas compostas por vagabundos, militares, trabalhadores, alunos) nos lugares fechados, atribuindo a cada indivíduo o seu lugar. Em seguida, é preciso controlar o emprego do tempo que racionaliza a ação. Enfim, o trabalho tornado obrigatório dá lugar a um controle fechado. Surge uma pedagogia do movimento, pelo registro e classificação dos indivíduos, a qual persiste até hoje em nossas escolas. A disciplina persegue o aluno, o louco, o delinqüente, o doente, o trabalhador. Escola, hospitais, fábricas se tornam prisões e as prisões, por sua vez, se tornam escolas, hospitais e fábricas. 
A educação física torna-se um projeto social de normalização dos corpos. O corpo desejante, lúdico, poético é abandonado em proveito de um corpo disciplinado. A cultura esportiva, onipresente, assujeita o corpo a uma ordem educativa na qual o corpo é dominado, até mesmo negado. $\mathrm{O}$ ascetismo dos treinamentos e o esforço, até mesmo o sofrimento, promete a ordem e o progresso. A base da organização social na escola é a referência à ordem, mas também ao silêncio e a imobilidade. Há sempre uma ordem estruturando um espaço específico, fechado, não flexível, raramente pensado em termo de estética, de cores, de ambiência, tanto que a maior parte das escolas veicula uma feiúra crônica, uma tristeza endêmica, uma pobreza, até mesmo uma negação dos sentidos dos alunos. Esse espaço padronizado, rígido, fixo não desvaloriza a tarefa do professor e do aluno? Esse espaço não restringe a criação e a liberdade lúdica? (LEFÈVRE, 2000).

Todo espaço organizacional reflete o funcionamento da instituição, mas também seus valores e regras. A escola torna-se, então, um assentamento sócio-espacial que produz comportamentos. O corpo do aluno ideal é o corpo imóvel, sentado no seu lugar, em silêncio, fixo. A hierarquia administrativa é igualmente territorializada, o que determina um sistema de poderes simbólicos em torno do corpo do aluno. Em prol de uma hierarquia rígida, perde-se aos poucos a riqueza da relação horizontal entre professor e aluno, na medida em que não há, no sentido estrito, professor ou aluno, mas apenas posições e papéis sociais constituídos em uma interação simbólica. Um professor de educação física escolar pode ser um aluno em um curso de pósgraduação, por exemplo. Estamos sempre nos deslocando de forma líquida entre papéis. Outro fator estruturante da vida social na escola é o tempo caracterizado por uma divisão estrita, até mesmo monótona. $\mathrm{O}$ inesperado não tem lugar. Só o programado, o organizado, o planificado, o planejado. O aluno, a educação, o tempo são sempre planejados, programados.

Nos cursos de ensino superior em Educação Física, o modelo anátomo-fisiológico permanece de maneira predominante para compreender o corpo, padronizando as representações corporais dos futuros professores de educação física. Outras instituições, a família, a Igreja, as Forças Armadas participam igualmente dessa construção de um corpo "apto" a viver em nossa sociedade. O objetivo é a civilidade do corpo (atualmente em voga a "cidadania") e, em outros termos, uma incorporação dos valores dominantes. 
Percebemos, segundo Lefèvre (2000), uma ortodoxia corporal pelas atividades esportivas. Os espaços esportivos impõem um código preciso, regrado, fixo pelo dispositivo institucional. Nesse sentido, não há espaço para o jogo, o lúdico, a dança. Nessa ânsia por transformar a educação física escolar em educação esportiva, o brincar perde espaço. Torna-se atividade deslegitimada e não eficaz para os propósitos de formação de atletas. Winnicott (1975) ressalta que o brincar produz sociabilidade, saúde, satisfação, prazer. O brincar é uma experiência criativa na continuidade espaço-tempo. Basicamente o brincar é uma forma de viver. No entanto, essa forma de viver é considerada incompatível com as demandas políticas de governos que elaboram um discurso de valorização do esporte olímpico, mas não se preocupam em resgatar a educação pública brasileira.

Para Lefèvre (2000), a ortodoxia corporal pelas atividades esportivas também se expressa na temporalidade do universo escolar que se constrói de maneira imutável pela divisão do emprego de um tempo não flexível e um ritmo escolar estranho aos ritmos biológicos das crianças. A amplificação desse fenômeno é exacerbado nas práticas esportivas pelo emprego do cronômetro e pela medida informatizada das performances individuais. A motricidade do aluno ideal é a ausência de mobilidade, exceto na prática esportiva. Todas as circulações são canalizadas, mesmo no pátio de recreação sempre vigiado. Na educação física, o projeto é de desenvolver uma mobilidade do controle, do domínio, da eficácia pela técnica. A aprendizagem motora não é para a vida, mas para o desempenho esportivo. O olhar sobre o corpo se faz com respeito aos rígidos padrões e normas corporais do movimento. Alem disso, no contexto das atividades esportivas, a relação entre alunos se estabelece majoritariamente sobre o modelo de enfrentamento e duelo.

Em resumo, a mensagem desenvolvida pela instituição escolar de imposição de regras, de condutas eficazes, está cada vez mais estabelecida no discurso esportivo pré-Olimpíada. A corporeidade se constrói, aqui, pelo exercício e pela repetição. O gosto pela retidão, as filas, a ortopedia, o valor do esforço, a norma são os elementos estruturantes que asseguram o mito do domínio racional. Esse corpo é economicamente correto, menos doente, acredita-se. Difundem-se, inclusive, idéias e representações de que as aptidões desenvolvidas no esporte são transferíveis para a vida profissional, já que o corpo atlético se tornou o símbolo da conquista 
desse século. A ascese burguesa pelo trabalho não escapa às práticas esportivas.

Essa "nova" educação física voltada para a formação de atletas olímpicos que deslegitima outras manifestações da cultura corporal não leva em conta a produção sócio-cultural do atleta. Isto é, formar um atleta passa pela condição de capital cultural, econômico e social. Bourdieu (1983) ao escrever um texto intitulado "Como é possível ser esportivo?", ressalta que o gosto pelo esporte enquanto prática ou espetáculo e os princípios que os agentes sociais escolhem entre as diferentes práticas ou consumos esportivos que lhes são oferecidos como possibilidade de um dado momento são produtos de um habitus e de um campo. O sistema de instituições e de agentes vinculados ao esporte tende a funcionar como um campo, agora cada vez mais hegemônico.

Tenta-se ocultar que a história do esporte é uma história das técnicas motoras produzidas em determinadas condições sociais, culturais e políticas. O discurso ideológico veiculado é que o esporte está acessível a todos, independente das condições de sua produção (FLEURIEL, 20003).

Além disso, o imaginário social esportivo veicula uma imagem de pureza, de amizade, o local onde as nações se reconciliam e as diferenças desaparecem. O esporte está sempre exaltando o altruísmo e a cooperação, mas na verdade trata-se de uma mitologia da solidariedade. $\mathrm{O}$ esporte competitivo implica em obediência a regras, a ordem e a hierarquia. O corpo é um instrumento que deve se tornar eficiente e rentável. Os povos utilizam a supremacia esportiva para ressaltar simbolicamente a supremacia político-econômica (LEFÉVRE, 1998).

Para Bourdieu (1979, 1983), o esporte é um objeto de lutas entre classes sociais. O esporte institucionalizado no século XIX na Europa teve por objetivo adestrar e vigiar os corpos. Os esportes eram vistos como meios de ocupar a menor custo os adolescentes e jovens. Era um meio extremamente econômico de mobilizar, ocupar e controlar. A definição moderna do esporte é, portanto, parte integrante de um ethos das classes dominantes. O capital econômico e cultural influenciam a escolha dos esportes produzindo hierarquizações entre esportes das elites e esportes das massas. Por acaso, nossos governantes pretendem construir piscinas nas escolas públicas com objetivo de formar atletas para natação? Por acaso, nossos governantes pretendem construir quadras de tênis ou salas de esgrima nas escolas públicas? 
O máximo que pretendem fazer é construir uma quadra polivalente nas escolas.

\section{Corpo legítimo e corpo bár- baro}

Para aqueles que almejam que o Brasil exerça algum grau de supremacia olímpica em 2016, o corpo legítimo é o corpo equilibrado, forte, veloz, técnico. O corpo dionisíaco, pulsional, expressivo, lúdico, desejante deve ser apagado. A escola e a educação física, no seu projeto pré-olímpico, deverão ao longo desses próximos anos se empenharem em lutar contra esse corpo estrangeiro, ou seja, esse corpo não civilizado que sempre insiste em tomar forma nas aulas de educação física. Trata-se de erradicar esse corpo animal, livrá-lo das pulsões, dessa parte incontrolável da sexualidade, de banir a alteridade e até mesmo de corrigir os corpos mal posicionados, mal coordenados dos alunos.

A educação física para esses que anseiam pela primazia do esporte é estruturada pelo campeão sacrificador (o vencedor), a vítima sacrificada (o vencido) e os expectadores ansiosos que projetam suas angústias de sociabilidade sobre o afrontamento dos campeões (LEFÈVRE, 2000). Qual seria a alternativa a esse modelo?
Talvez seja resgatar a ludicidade, o jogo, o brincar. Huizinga (1988) ressalta que a oficialização do esporte implica na maior parte da vezes em perda das características do lúdico. Na Inglaterra, berço da vida esportiva moderna, as regras se tornavam cada vez mais rigorosas e complexas. Eram estabelecidos recordes de altura, de velocidade ou de resistência superiores a tudo quanto antes foi conseguido. Essa sistematização e regulamentação cada vez maior do esporte implicaram gradativamente em perda de parte das características lúdicas. O espírito do profissional não é mais o espírito lúdico, pois Ihe falta espontaneidade, despreocupação, características vitais da educação física lúdica.

A prática esportiva massificada nas escolas para produzir grandes atletas para as Olimpíadas de 2016 é a transformação da educação física em desporto, por conseguinte, em sinônimo de verificação da performance. Quando a educação física vai perdendo seu caráter lúdico, transformador, dionisíaco, estético, desejante, as aulas deixam de ser sagradas e tornamse cada vez mais individualistas e voltadas a meritocracia moderna. O esporte se torna um comércio, um negócio e não uma prática prazerosa para alunos. Abandonamos cada vez mais a essência lúdica do ser humano. 
Nossa defesa não é pelo fim das práticas esportivas na educação física escolar. Pelo contrário, estudos transversais e longitudinais evidenciam que atividades físicas da educação física escolar, incluindo as esportivas, contribuem para o bemestar, promoção da saúde e qualidade de vida de crianças, adolescentes e jovens (CARLSON et al, 2008; DATAR, STURM, 2004; FERREIRA, 2001; MCKENZIE et al 1996).

O que não podemos deixar de buscar é a incorporação de todas as dimensões da corporeidade na educação física, incluindo o esporte. No entanto, não podemos deixar de atentar para o fato de que os sentidos e significados atribuídos pelos alunos as distintas manifestações da cultura corporal nos ajudam a ampliar o conceito de práticas corporais educacionais. Silva et al (2008) afirmam que o corpo, estudado pelo referencial cultural, é considerado como síntese e não como fragmento. Síntese de determinado contexto, de uma identidade social. As marcas inscritas no corpo, as pinturas, as roupas, os adornos, a maneira como gesticula, as práticas corporais que se realizam são registros de contexto social e histórico bastante específico. Para compreendermos esses significados culturais é preciso identificar intenções, emoções, expressões presentes no cotidiano escolar e não apenas im- por práticas esportivas impessoais com fins mercadológicos.

Como diz Garaudy (1980), a educação a partir do movimento não tem o objetivo de habilitar alguém para uma carreira bemsucedida na hierarquia social, ao triunfo numa partida desportiva ou à destruição eficaz de um concorrente, mas o de desenvolver o amor pela aptidão para a criatividade pela expressão corporal pessoal. Esse objetivo é, ao mesmo tempo, uma experiência estética fundamental e um engajamento social. É uma estética da existência. Nossa tarefa é reinventar o corpo na escola pelo viés de uma motricidade artística que tomaria da dança, do teatro, do circo, da rua e das brincadeiras uma educação através do e pelo movimento não submisso à prática esportiva.

\section{Referências}

ABRAHÃO, J. Financiamento e Gasto Público da Educação Básica no Brasil e comparações com alguns países da OCDE e América Latina. Educação \& Sociedade, Campinas, v. 26, n. 92, p. 841-858, out. 2005.

BENTHAM, J. The Principles of Morals and Legislation. New York: Prometheus Books, 1988. BOLTANSKI, L. As classes sociais

e o corpo. 4 ed. Tradução de 
Regina Machado. São Paulo: Paz e Terra, 2004. - Les usages sociaux du corps, Annales E.S.C, n. 26, v. 1, p. 205-233, 1971.

BORDELEAU, L-P. Un nouveau paradigme: le corps sportif. Philosophiques, v. 12, n. 1, p. 33-51, 1985.

BOURDIEU, P. Questões de

Sociologia. Rio de Janeiro: Marco Zero, 1983.

. La distinction. Paris: Ed. de Minuit, 1979.

BRUGNEROTTO, F.; SIMÕES, R. Caracterização dos Currículos de Formação Profissional em Educação Física: um enfoque sobre saúde. Physis: Revista de Saúde Coletiva, v. 19, n. 1, p. 149-172, 2009.

CARLSON, S.A.FULTON, J.E.; LEE, S.M; MAYNARD, L.M.; BROWN, D.R.; KOHL, H.W.; DIETZ, W.H. Physical education and academic achievement in elementary school: data from the early childhood longitudinal study. American Journal of Public Health, v. 98, n. 4, p. 721-721, 2008.

DATAR, A.; STURM, R. Physical education in elementary school and body mass index: evidence from the early childhood longitudinal study. American Journal of Public Health, v. 94, n. 9 , p. 1501-1506, sep. 2004.
DURET, P.; ROUSSEL, P. Le corps et ses sociologies. Paris: Nathan, 2003.

ELIAS, N. O Processo Civilizador. Volume 1: Uma História dos Costumes. Tradução de Ruy Jungmann. Rio de Janeiro: Jorge Zahar, 1993.

O Processo Civilizador. Volume 2: Formação do Estado e Civilização. Tradução de Ruy Jungmann.Rio de Janeiro: Jorge Zahar, 1994.

FERREIRA, M. S. Aptidão Física e Saúde na Educação Física Escolar: ampliando o enfoque. Revista Brasileira de Ciências do Esporte, Campinas, v. 22, n. 2, p. 41-54, 2001.

FLEURIEL, S. Les vertus généalogiques du sport. SocioAnthropologie (Jeux / Sports), n. 13, 2003.

FOUCAULT, M. Histoire de la sexualité: la volonté de savoir, Paris: Gallimard, 1976.

. Surveiller et Punir: naissance de la prison Paris: Éditions Gallimard, 1993. Résumé des cours (19701982). Paris: Julliard, 1989.

FOURNIER, M. Suveiller et punir: naissance de la prison. Sciences Humaines, n. 3 (Foucault, Derrida, Deleuze: Pensées rebelles), maio./jun. 2005.

FREUD, $S$. Trois essais sur la théorie de la sexualité. Paris: Gallimard, 1962. 
Métapsychologie. Paris: Gallimard, 1968 . Essais de psychanalyse. Paris: Payot, 1981.

GARAUDY, R. Dançar a Vida. 4 ed. Tradução de Glória Mariani e Antônio Guimarães Filho. Rio de Janeiro: Nova Fronteira, 1980.

HUIZINGA, J. Homo ludens: sur la fonction sociale du jeu. Paris: Gallimard, 1988.

KANT, I. Sobre a Pedagogia. Tradução de Francisco Cock Fontanella. 4 ed. rev. Piracicaba: UNIMEP, 2004.

LE BRETON, D. A Sociologia do Corpo. Tradução de Sonia Fuhrmann. Petrópolis: Vozes, 2006.

LE BRETON, D. Antropología del Cuerpo y Modernidad. Buenos Aires: Nueva Vision, 2002. (Cultura y Sociedad).

LE FRANC, C. Microphysique du pouvoir. Sciences Humaines, $n$. 3 (Foucault, Derrida, Deleuze: Pensées rebelles), maio./jun. 2005.

LEFÈVRE, B. Corps baroque et éducation physique scolaire. Corps \& Culture, n. 5, 2000. . Mythologie de la solidarité sportive. Corps \& Culture, n. 3, 1998.

LEHER, R.; LUCAS, L. C. G.. Aonde vai a Educação Pública Brasileira? Revista Educação \& Sociedade, Campinas, v. 22 , n. 77 , p. 255266, dez. 2001.
LEHER, R. Educação no Governo Lula da silva: reformas sem projeto. Revista Adusp, São Paulo, n. 34, p. 46-54, 2005.

LIOTARD, P. L'E.P. n'est pas jouer : la maîtrise pédagogique du plaisir en éducation physique. Corps \& Culture, n. 2 (Plaisir du corps, Plaisir du sport), 1997.

MAUSS, M. As Técnicas Corporais. In: MAUSS, M. Sociologia e Antropologia: Volume II. São Paulo: Pedagógica e Universitária, 1974.

MARIE, J-F. Plaisir imaginaire et imaginaire du plaisir: Approche sociologique du plaisir en Education Physique et Sportive. Corps \& Culture, n. 2 (Plaisir du corps, Plaisir du sport), 1997. MCKENZIE, T.L.; NADER, P.R; STRIKMILLE, P.K.; YANG, M.; STONE, E.J.; PERRY, C.L.; TAYLOR, W.C.; EPIING, J.N.; FELDMAN, H.A.; LUEPKER, R.V.; KELDER, S.H.

School physical education: effect of the Child and Adolescent Trial for Cardiovascular Health. Preventive Medicine, v. 25, n. 4, p. 423-431, jul./aug. 1996.

MILL, J.S. Utilitarianism. Virginia: IndyPublish, 2005.

PIAGET, J. Le jugement moral chez I'enfant. Paris : PUF, 2000. . La naissance de l'intelligence chez I'enfant. Paris : Delachaux et Niestlé, 1963. 
. La construction du réel chez I'enfant. Paris : Delachaux et Niestlé, 1990.

PINTO, J.M.R. A política recente de fundos para o financiamento da educação e seus efeitos no pacto federativo. Educação \& Sociedade, Campinas, v. 28, n. 100, p. 877-897, out. 2007.

SAMPAIO, M.M.F.; MARIN, A.J. Precarização do Trabalho Docente e seus Efeitos sobre as Práticas Curriculares. Educação \& Sociedade, Campinas, v. 25, n. 89, p. 1203-1225, set./dez. 2004.

SILVA, C.L.; VELOZO, E.L.; RODRIGUES JÚNIOR, J.R. Pesquisa qualitativa em Educação Física: possibilidades de construção de conhecimento a partir do referencial cultural. Educação em Revista, Belo Horizonte, n. 48, p. 37-90, dez. 2008
SYNNOTT, A. The Body Social: Simbolism, Self and Society. London and New York: Routledge, 1993.

VEJA. São Paulo: Abril, n. 40, ano 42, edição 2133, 7 out. 2009.

VEJA RIO. Rio de Janeiro, n. 39, ano 19, edição 2132, 30 set. 2009.

VINSONNEAU, G. La Construction Sociale du Corps. Ville-EcoleIntégration Enjeux, n. 6, dez. 2002.

WACQUANT, L.J.D. Corps et ame: carnets ethnographiques $d^{\prime}$ um aprrenti boxeur. Paris: Agone, 2002.

WINNICOTT, D.W. O Brincar e a Realidade. Rio de Janeiro: Imago, 1975.

Recebido: 02/fevereiro/2010. Aprovado: 12/abril/2010. 